\title{
COORDINATION OF METABOLISM, ACID-BASE REGULATION AND HAEMOCYANIN FUNCTION IN CEPHALOPODS
}

\author{
H. O. PÖRTNER
}

Alfred-Wegener-Institut für Polar- und Meeresforschung, Biologie I/Ökophysiologie, Columbusstraße, D-27568 Bremerhaven, FRG

The role of cephalopod haemocyanins in oxygen transport is analysed in the light of the coordination of metabolism, acid-base regulation and gas exchange processes. Results obtained in squid, the most active among cephalopod species, indicate that the pH dependence of their haemocyanin supports a $\mathrm{PO}_{2}$ buffer function for the pigment. The release of base equivalents from the tissue during aerobic exercise and the minimal release of protons during anaerobic octopine formation protect arterial $\mathrm{pH}$ and, thus, oxygen binding. The extent of respiratory acidification and haemocyanin deoxygenation on the venous side is higher in blood returning from the mantle than from the head. In vivo blood gas measurements reported for squid and for other cephalopod species support the conclusion that $\mathrm{CO}_{2}$ accumulation and respiratory acidification of the blood occur in excess of the effect expected from the consumption of haemocyanin bound $\mathrm{O}_{2}$ and $\mathrm{RQ}$ values derived from protein catabolism. This suggests that a considerable fraction of the oxygen consumed by the animal enters via the skin, especially in the mantle. Model calculations demonstrate that skin $\mathrm{O}_{2}$ uptake in the mantle increases during activity in squid. In other cephalopod species like cuttlefish, the special process of arterial $\mathrm{CO}_{2}$ binding to oxygenated haemocyanin and its release during venous deoxygenation may provide the excess $\mathrm{CO}_{2}$ required for venous acidification. All of these processes allow the classical Bohr effect to function supporting oxygen loading at the gills and oxygen unloading in the tissues. The large $\mathrm{pH}$-dependent cooperativity and the Bohr effect combine to maximize the $\mathrm{PO}_{2}$-buffer function of the respiratory pigment. These adaptations probably evolved after the ancestors of modern cephalopods lost their shells and locomotor activity assumed a greater role in their lifestyle.

KEY WORDS: acid-base status, cephalopod, haemocyanin, pH dependence, metabolism, skin respiration, squid

\section{INTRODUCTION}

Cephalopods exhibit the highest rates of aerobic metabolism among marine invertebrates and, among cephalopods, the highest rates are found in muscular squid. Squid metabolism at rest and during exercise is even higher than the respective metabolic rates of salmonid fish which exhibit similar performance characteristics (O'Dor and Webber, 1986, cf. Wells, this volume). Although differences are large among cephalopods, e.g. between octopods and squid, the metabolism of most cephalopods exceeds the rates found among other invertebrate groups which also rely on haemocyanin for oxygen transport. Oxygen transport to tissues has to be maximized to cover the metabolic requirements. However, cephalopods are evolutionarily constrained by having an extracellular oxygen carrier. Buffering of $\mathrm{pH}$ changes is reduced in extracellular blood pigment solutions when compared with vertebrate cellular systems. The oxygen carrying capacity of bloods containing haemocyanins is limited by an increase in blood viscosity and colloid-osmotic pressure with increasing respiratory protein levels (Mangum, 1990). This is only partly 
compensated for by the maximization of molecular weight and of the numbers of oxygen molecules bound to each haemocyanin molecule. Thus, while fish blood binds 4-5 mmoles $\mathrm{O}_{2}$ per 1 , cephalopod blood binds only between 1 and 2 mmoles $\mathrm{O}_{2}$ per 1 . To meet the high demand for oxygen at rest and during exercise it is then necessary for the circulatory system to pump large amounts of blood, with close to maximum oxygen extraction on each cycle (Houlihan et al., 1986, Shadwick et al., 1990, O’Dor et al., 1990).

Generally, an extracellular respiratory pigment is more directly exposed to any changes in extracellular fluid composition than it would be in a protected cellular environment. This should limit the ability of the system to maintain a constant environment for blood pigment function. It may also prevent it from modulating oxygen binding as extensively as in vertebrate red blood cells. The present study investigates whether these predictions really hold true in cephalopods, since haemocyanin oxygen tranport is nonetheless able to support the high rates of oxygen consumption found in this group, especially in the more active squid (O'Dor and Webber, 1986).

\section{MATERIALS AND METHODS}

Previous conclusions concerning haemocyanin function in cephalopods are based on in vitro analyses of oxygen binding and on in vivo measurements of arterial and venous blood gas parameters. These studies are scarce, especially those focussing on the most vigorous and fragile of these animals, squid. An early study which reported in vivo blood gas measurements in squid was performed on restrained (nailed to a board) animals (Redfield and Goodkind, 1929). Analyses in unrestrained squid have only recently been reported (Pörtner et al. 1991, 1993). Free swimming animals were exercised in a swim tunnel and subjected to increasing water speeds until they collapsed from exhaustion. These experiments were possible, based on an improved procedure of anaesthesia and a cannulation technique both of which allowed for full recovery and performance of the unrestrained animal. The number of analysed parameters was increased and, in addition to blood gas and acid-base parameters, key substrates and products of energy metabolism were investigated. The intracellular acid-base status was studied using recently developed techniques for the accurate determination of intracellular $\mathrm{pH}$, buffer values, $\mathrm{CO}_{2}$ contents and $\mathrm{CO}_{2}$ partial pressures in tissue homogenates (Pörtner 1990 a, Pörtner et al., 1990). For the present study, the respective in vivo blood and tissue gas and acid-base data (Pörtner et al., 1991) and the results obtained from an investigation of the features of exercise metabolism (Pörtner et al., 1993) were combined with an unconventional analysis of the effects of $\mathrm{pH}$ on haemocyanin oxygen binding (Pörtner, $1990 \mathrm{~b}$ ) to develop a quantitative picture of the correlation between the changes in the intraand extracellular acid-base status and metabolic and gas exchange processes (for the respective methodology see Heisler, 1986; Pörtner, 1987 b). Using the resulting quantitative picture of acid-base and metabolic effects on haemocyanin oxygen transport, the analysis also focusses on how the haemocyanin design meets the requirements of cephalopod life style and performance and on how its function may be affected by gas and ion exchange between tissues and blood and by changes in environmental parameters (see also Bridges and Brix et al., this volume). 


\section{RESULTS AND DISCUSSION}

\section{Bohr and Haldane effects}

Cephalopod haemocyanins are characterized by a high sensitivity to $\mathrm{pH}$. The change in oxygen affinity is traditionally quantified by the Bohr coefficient $\Delta \log \mathrm{P}_{50} / \Delta \mathrm{pH}$ which represents the change in $\mathrm{P}_{50}$ (the $\mathrm{PO}_{2}$ at which the pigment reaches $50 \% \mathrm{O}_{2}$ saturation) with $\mathrm{pH}$ (cf. Bridges and Brix et al., this volume). The change in affinity with $\mathrm{pH}$ is elicited by proton binding to or release from the pigment. This process also affects $\mathrm{CO}_{2}$ loading in the tissues during deoxygenation and $\mathrm{CO}_{2}$ unloading at the gills during oxygenation. The capacity of the pigment to contribute to $\mathrm{CO}_{2}$ transport is quantified by the Haldane coefficient $\Delta \mathrm{HCO}_{3} / \Delta \mathrm{cHcyO} \mathrm{O}_{2}=\Delta \mathrm{cHcyH} / \Delta \mathrm{cHcyO}{ }_{2}$, which indicates that proton and oxygen turnover are interdependent processes $\left(\mathrm{cHcyH}, \mathrm{cHcyO}_{2}\right.$ : concentrations of protons or oxygen bound to the Haemocyanin, HCY). Therefore, Haldane- and Bohr-coefficients are quantitatively equivalent as expressed by the linkage equation (Wyman, 1964). In brief, the traditional view of the function of Bohr and Haldane effects, valid for most vertebrate haemoglobins with Bohr coefficients significantly above -1 (minus one), for example, would lead to the following qualitative description:

Owing to respiratory $\mathrm{CO}_{2}$ release, blood $\mathrm{pH}$ is high at the lungs or gills. High $\mathrm{pH}$ favours oxygen binding and associated proton release. The protons titrate excess bicarbonate and enhance the quantity of released $\mathrm{CO}_{2}$. As the blood passes through the tissues, blood $\mathrm{pH}$ is lowered by metabolic $\mathrm{CO}_{2}$ and causes oxygen to be released from the pigment, thus maintaining $\mathrm{PO}_{2}$ at higher values than would occur without the existence of a Bohr effect. Protons are bound in exchange, enhancing bicarbonate formation from $\mathrm{CO}_{2}$ and, thus, the amount of $\mathrm{CO}_{2}$ taken up by the blood. $\mathrm{CO}_{2}$ and $\mathrm{O}_{2}$ transport are closely linked to maximize gas exchange. The ratio between transported $\mathrm{CO}_{2}$ and $\mathrm{O}_{2}$ quantitites (i.e. the respiratory quotient, $\mathrm{RQ}$ ) depends upon the metabolic substrate $(R Q=0.7-1)$.

This traditional picture has been questioned for the cephalopods, since high Bohr and Haldane coefficients $(<-1)$ prevail, indicating that high proton turnover occurs at the protein molecule (Lykkeboe et al., 1980). The major energy source of cephalopods is protein which leads to an expected overall RQ of around 0.85 (Agnisola et al., 1991, cf. Lee, this volume). Taking the respective proton turnover and molar quantities into account, Pörtner (1990 b) calculated for Illex illecebrosus that, based on the ratio of $\mathrm{O}_{2}$ and $\mathrm{CO}_{2}$ quantities taken up and released during branchial gas exchange, proton consumption during venous deoxygenation would exceed respiratory acidification leading to an elevation of venous pH by 0.07 units above arterial $\mathrm{pH}$. The alkalosis would impair oxygen delivery since the haemocyanin would bind oxygen even more strongly and release it only at lower $\mathrm{PO}_{2}$ values. Thus, the capillary-cellular $\mathrm{PO}_{2}$ gradient and oxygen flow to mitochondria would be reduced.

This situation has led to an intense discussion of the special function of Bohr and Haldane effects in cephalopods. Lykkeboe et al. (1980) proposed that oxygen-linked $\mathrm{CO}_{2}$ binding occurs in Sepia latimanus: During oxygenation excess $\mathrm{CO}_{2}$ would be bound at the gills and released in the tissue to balance the venous alkalosis. This mechanism would cause elevated $\mathrm{CO}_{2}$ levels in the tissue and is quantified by the functional Haldane coefficient $\Delta \mathrm{CcO}_{2} / \Delta \mathrm{HcyO}_{2}>-1$ (Brix et al., 1981). The problem with this model is that oxygen-linked $\mathrm{CO}_{2}$ binding may not be present in all haemocyanins with Bohr coefficients $<-1$. This process could not be found in some octopod and squid species (e.g.Octopus dofleini, Illex illecebrosus, Loligo pealei, Lykkeboe and 
Johansen, 1982; Miller and Mangum, 1988; Pörtner, 1990 b). In those species without $\mathrm{O}_{2}$-linked $\mathrm{CO}_{2}$ binding, the function of the Bohr effect is discussed only as enhancing arterial oxygen loading under conditions when an increase in ventilation causes respiratory alkalosis (Lykkeboe and Johansen, 1982; Brix et al., 1989).

\section{Metabolic and Ionic Influences on Tissue and Blood pH}

Respiratory acidification by accumulating $\mathrm{CO}_{2}$ is only one process causing venous blood $\mathrm{pH}$ to fall below arterial $\mathrm{pH}$. It has previously been overlooked that anaerobic metabolism in squid is able to cause an acidosis during exercise according to the same principles as in vertebrates (for review see Pörtner, 1987 a). Cephalopods form octopine during anaerobic exercise (Grieshaber and Gäde, 1976; Gäde, 1980). According to its physicochemical properties, octopine is a weak acid which would not cause an acidosis. However, octopine accumulation involves the net formation of glycolytic pyruvate which is linked to proton release. It was recently confirmed that octopine formation leads to proton accumulation in fatiguing squid (Pörtner et al., 1991). The question arises, whether octopine formation and other metabolic processes would exert an influence on blood pH. Our data (quantified in Figures 1

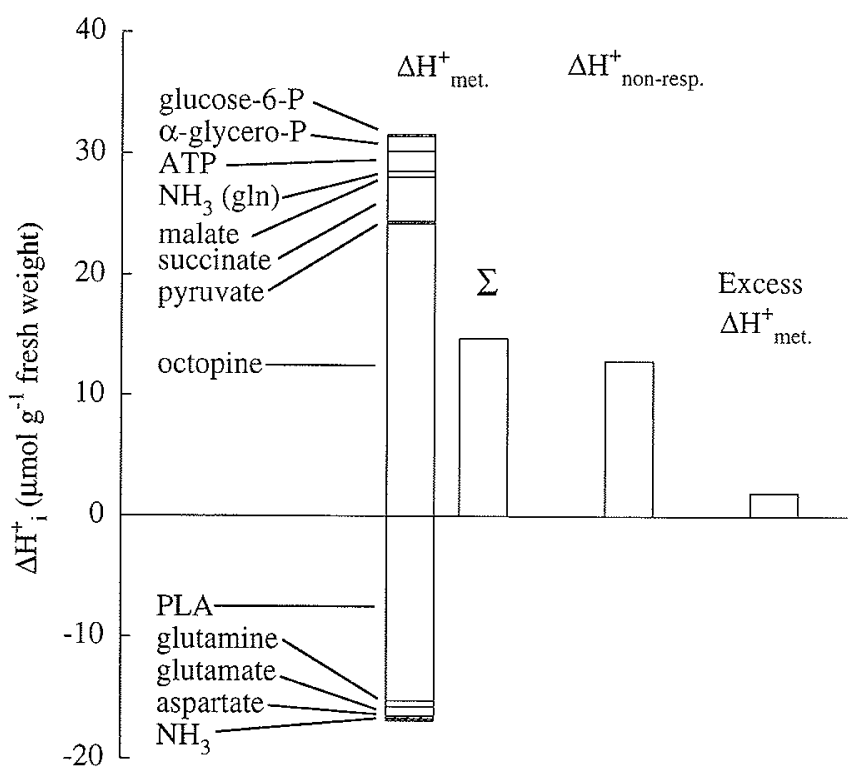

Figure 1 Starting from mean values for resting controls the evaluation of changes in metabolite levels and associated proton turnover $\left(\Delta \mathrm{H}^{-}\right)$leads to a comparison of the sum $(\Sigma)$ of intracellular (i) metabolic (met.) and non-respiratory (non-1esp.) proton quantities in the mantle of each exercised squid specimen (Illex illecebrosus). Data are shown for the animal which exhibited the highest rate and extent of proton accumulation during muscular fatigue. A slight unexplained excess of metabolic protons in this specimen suggests that these protons were released into the blood. The respective data for all investigated animals are depicted in Figure 2. Metabolic proton quantities were calculated from changes in metabolite levels (Pörtner, 1987 a). Non-respiratory protons were evaluated from the respective changes in acid-base parameter's during fatigue (Pörtner, 1987 b). (For further explanations see text, based on data by Pörtner et al. 1991 and in press;-P, bound inorganic phosphate; gln, glutamine; PLA, phospho-L-arginine). 


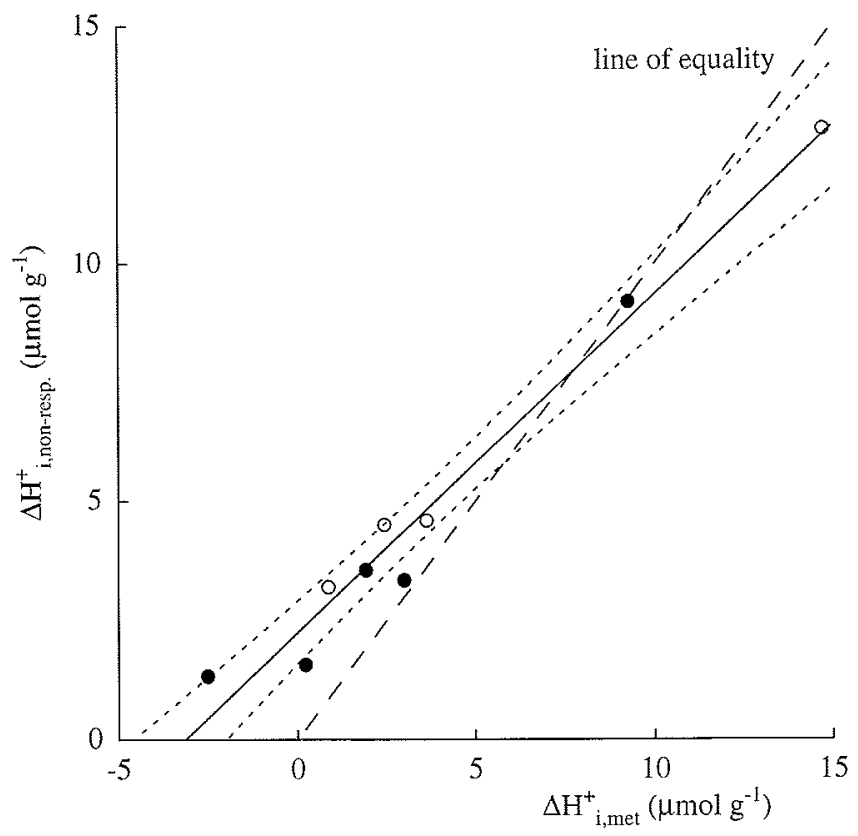

Figure 2 Comparison of intracellular non-respiratory and metabolic protons in the mantle of squid (Illex illecebrosus) sacrificed after fatigue from exercise $(0)$ or after $10^{\prime}$ of recovery $(\bullet)$. The analysis of data for all experimental animals (following the principles depicted in Figure 1) reveals that, with progressive metabolic proton accumulation, an inital non-respiratory base deficit (i.e. a non-respiratory acidosis which cannot be explained by metabolic processes) becomes an excess of metabolic protons during maximum metabolic proton formation (dashed lines indicate the $95 \%$ confidence interval).

to 3) strongly suggest that such an influence is minimal and that protons and end products are recycled at the site of production, within the muscle cells of the mantle tissue:

Figure 1 shows an example of the analysis performed for each individual animal. The non-respiratory proton quantities found in the mantle acid-base status are compared with those provided by metabolic processes. In this specimen, which had the highest octopine levels of all fatigued animals, a small excess of metabolic protons is likely to cause some net proton release into the blood. However, such an excess of metabolic protons is only found with maximum metabolic acidification. The results for all investigated animals (Figure 2) reveal that, with less metabolic proton formation, a non-respiratory base deficit is apparent in the tissue, suggesting a net loss of base from the tissue during activity which is dimished with increasing metabolic acidification. Accordingly, the quantitative analysis of acid-base changes in the blood demonstrates that base accumulation occurred in excess of haemocyanin proton binding. This base excess is not completely balanced during maximum acidification of the mantle, suggesting that other tissues, possibly non-muscular and not involved in activity metabolism, provided base as well and helped to eliminate the effect of any protons leaking out of the mantle tissue (Figure 3).

Such a strategy, to minimize the release of metabolic protons and end products into the extracellular space, would limit the ability of cephalopods to form protons 


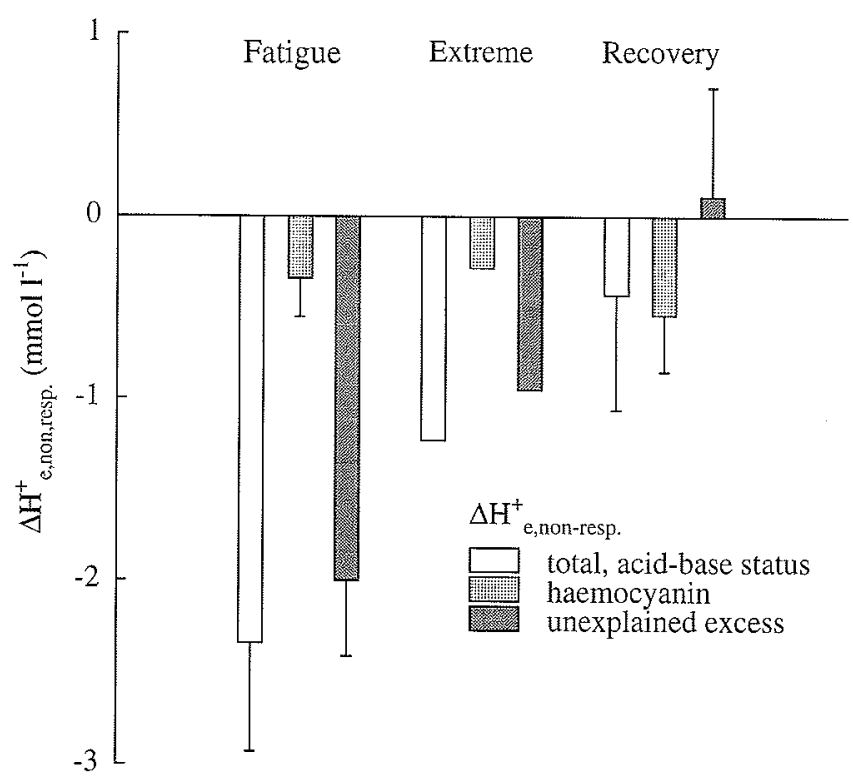

Figure 3 Comparison of non-respiratory changes in the acid-base status of the blood with the proton quantities bound by haemocyanin during deoxygenation in exercised and recovering squid (Illex illecebrosus). During fatigue a base excess remains which is not explained by proton binding during haemocyanin deoxygenation even with extreme metabolic acidification of the tissue. Rather it reflects the base loss observed in the mantle during exercise (cf. Figure 2 and text, mean $\pm \mathrm{SE}, \mathrm{n}=3$ to 5 , based on data by Pörtner, 1990 b; Pörtner et al., 1991).

in high quantities and thus to use anaerobic glycolysis for energy production to the same extent as found in exercising vertebrates. This limitation may be compensated for to some extent by the high phosphagen stores (phospho-L-arginine=PLA) found in squid mantle tissue. High quantities of accumulated protons and the use of dephosphorylated L-arginine ( $\mathrm{L}$-arg) in octopine formation promote phosphagen depletion owing to the participation of protons in the respective reactions (simplified equations, cf. Pörtner, 1987a):

$$
\begin{aligned}
& \mathrm{PLA}^{-}+\mathrm{MgADP}^{-}+\mathrm{H}^{+} \longrightarrow \mathrm{L}_{\text {-arg }}^{+}+\mathrm{MgATP}^{2-} \\
& \mathrm{L} \text {-arg }^{+}+0.5 \text { glucose } \longrightarrow \text { octopine }+\mathrm{H}^{+}
\end{aligned}
$$

By comparing Illex and Loligo we recently demonstrated that octopine formation and the associated intracellular acidification protected tissue ATP stores in Illex. Minor octopine formation and acidification in Loligo caused ATP levels to be more severely depleted, since only ADP would trigger transphosphorylation from the phosphagen under these conditions (Pörtner et al., 1993).

The observations that metabolic proton turnover and accumulation occur virtually exclusively in the tissue and that, additionally, net base is released into the blood strongly suggest that the blood is protected from being acidified by metabolic and ionic influences. Further studies must show whether this is a general 


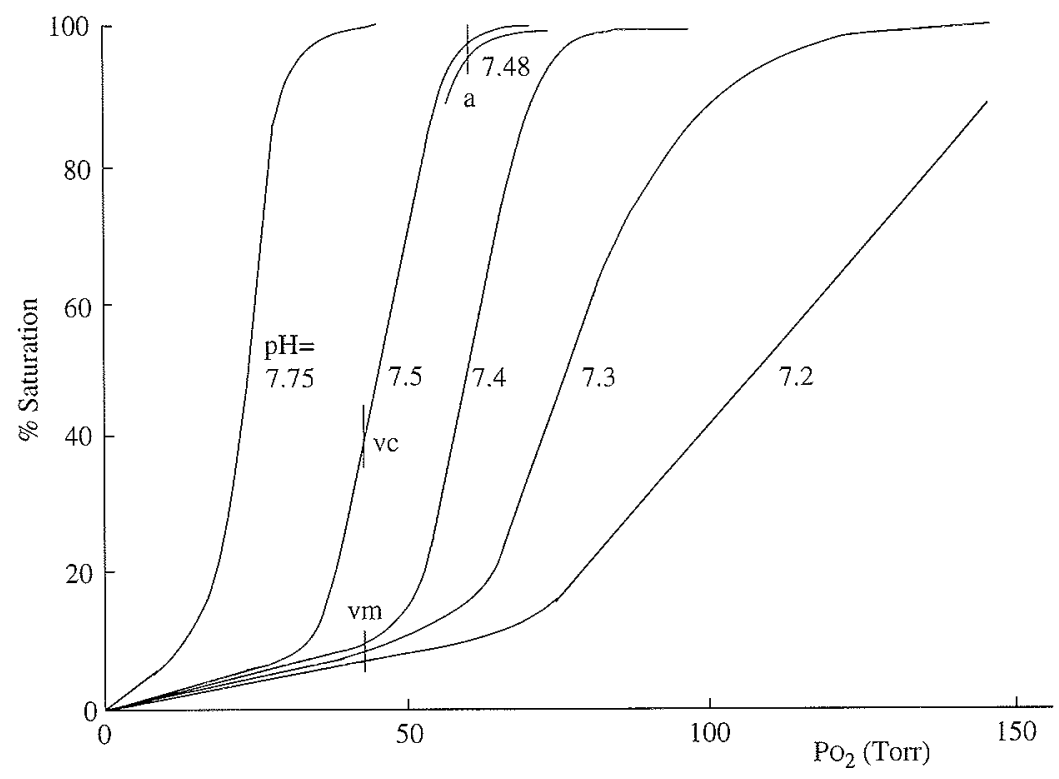

Figure 4 Traditional $\mathrm{Po}_{2}$ /saturation diagram constructed for Illex illecebrosus blood using the $\mathrm{pH} /$ saturation analysis (cf. Figures $6 \mathrm{~A}-\mathrm{D}$ ) by evaluating the changes in $\%$ saturation at constant $\mathrm{pH}(\mathrm{T}$ $\left.=15^{\circ} \mathrm{C}\right) . \mathrm{PO}_{2}$ saturation values missing from the original data set were evaluated considering the slopes of the respective isobars as they depend upon $\mathrm{pH}$ (cf. Pörtner, $1990 \mathrm{~b}$ ). Vertical lines depict minimum arterial (a) $\mathrm{Po}_{2}$ values required for full oxygenation under control conditions and the respective venous $\mathrm{PO}_{2}$ values in the head (ve, venous cephalic blood) or mantle (vm, venous mantle blood) at different venous $\mathrm{pH}$ values (Figure 6A).

feature in cephalopods. In the above mentioned context, this feature may be seen to maintain the function of the extracellular respiratory pigment haemocyanin (see below).

\section{An Analysis of the Effects of $p H$ on Oxygen Transport in vivo}

The large $\mathrm{pH}$ dependence of haemocyanin oxygen transport in cephalopods led to the development of an unconventional $\mathrm{pH} /$ saturation analysis for the presentation of $\mathrm{pH}$ effects on oxygen binding (used in Figures $6 \mathrm{~A}-\mathrm{D}$, Pörtner, $1990 \mathrm{~b}$ ). Using this approach, the $\mathrm{pH}$ dependence can be quantified in whole blood without the need to clamp $\mathrm{pH}$ by the addition of artificial buffers as required in weakly buffered cephalopod blood for the experimental construction of traditional $\mathrm{PO}_{2} /$ saturation diagrams (Figure 4, cf. Miller and Mangum, 1988). Lines in the $\mathrm{pH} / \mathrm{saturation}$ diagram are oxygen isobars illustrating how haemocyanin oxygenation changes with $\mathrm{pH}$ at constant $\mathrm{PO}_{2}$. Therefore, the isobars are suitable to show how $\mathrm{pH}$ should change to support a $\mathrm{PO}_{2}$ buffer function of the haemocyanin. The Figure also illustrates the change in $\mathrm{P}_{50}$ with $\mathrm{pH}_{50}$ and thus depicts the Bohr coefficient $\Delta \log \mathrm{P}_{50} / \Delta \mathrm{pH}$ in the context of $\mathrm{pH}$ effects below and above 50\% saturation. Slopes of the isobars are linear around $\mathrm{P}_{50}$ and show that maximum $\mathrm{pH}$ sensitivity is found in the range of $i n$ vivo $\mathrm{pH}$ (between 7.2 and 7.5 in Illex, cf. Figure 6A). This conclusion is not as evident from the traditional $\mathrm{PO}_{2} /$ saturation diagram (Figure 4) since a continuous plot of $\mathrm{pH}$ 


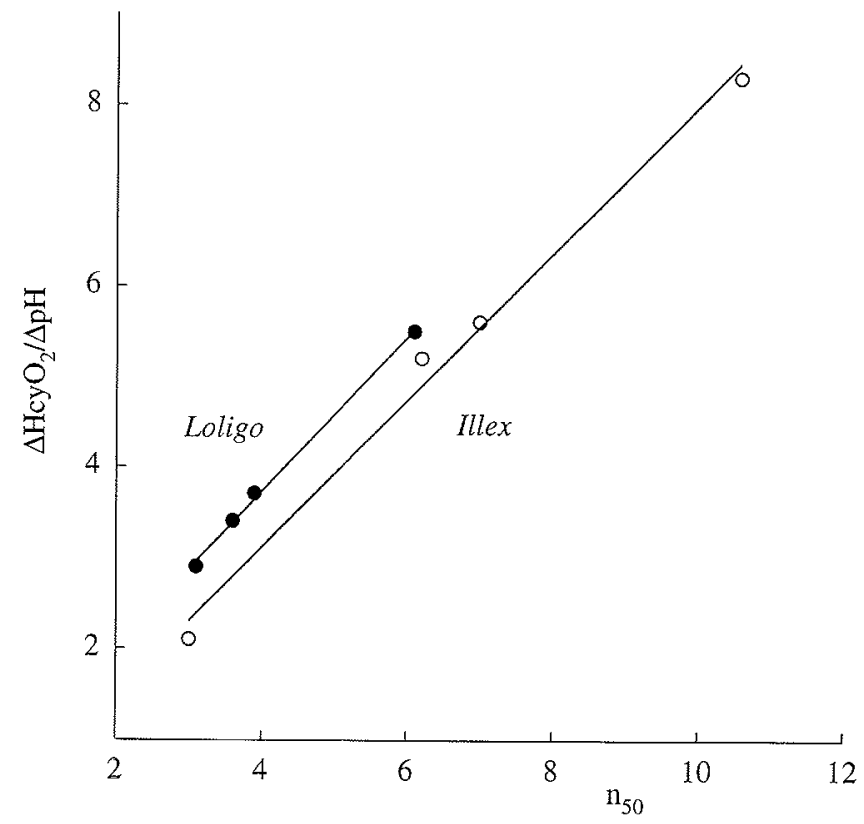

Figure 5 Correlation between the cooperativity of haemocyanin subunits $\left(n_{50}=\right.$ cooperativity at oxygen half-saturation, derived from the application of the Hill equation to a graphical analysis of cooperativity at constant $\mathrm{pH}$ using the $\mathrm{pH}$ /saturation diagram. Pörtner, 1990b) and the slopes of the oxygen isobar $\left(\Delta \mathrm{HcyO}_{2} / \Delta \mathrm{pH}\right)$ in the $\mathrm{pH} /$ saturation diagram (Figures $\left.6 \mathrm{~A}-\mathrm{D}\right)$. Variable slopes of the oxygen isobars are assumed to result from a $\mathrm{pH}$-dependent change in cooperativity (based on data by Pörtner, 1990b).

effects is not possible. Further advantages of a $\mathrm{pH} /$ saturation analysis arise: Not only may the traditional $\mathrm{PO}_{2} /$ saturation depiction be constructed by evaluating $\mathrm{PO}_{2}$ and $\%$ saturation at constant $\mathrm{pH}$ (Figure 4 ) but the Hill coefficients, $\mathrm{n}_{50}$, can also be evaluated as a measure of haemocyanin subunit cooperativity. Cooperativity strongly depends upon $\mathrm{pH}$ and its analysis is severely affected by $\mathrm{pH}$ changes in the blood which will always occur when haemocyanin oxygenation changes (owing to the interdependence of $\mathrm{H}^{-}$and $\mathrm{O}_{2}$ binding seen as Bohr and Haldane effects. Experimental construction of oxygen binding curves including the analysis of cooperativity is always associated with the respective fluctuations in $\mathrm{pH}$ ). The graphical method (Pörtner, $1990 \mathrm{~b}$ ) is suitable to exclude erroneous analyses of $n_{50}$ which may result from these $\mathrm{pH}$ fluctuations or the addition of artificial buffers. The highest cooperativity values reported for cephalopods result. The slopes of the isobars in the $\mathrm{pH} /$ saturation diagram (Figure 6) correlate well with the respective Hill coefficients (Figure 5). Maximum cooperativity in the range of in vivo $\mathrm{pH}$ minimizes the $\mathrm{pH}$ change required for deoxygenation. $\mathrm{pH}$ sensitivity is higher in the vigorous oceanic squid (Illex illecebrosus) than in the slower inshore species (Loligo pealei) suggesting that a maximization of $\mathrm{pH}$ sensitivity may coincide with a maximization of performance.

The diagram also depicts the extent to which the depletion of a potential venous reserve may depend upon either a decrease in $\mathrm{pH}$ (following one of the isobars) or just on a decrease in $\mathrm{PO}_{2}$ when the $\mathrm{pH}$ dependence of deoxygenation is restricted to a certain range of oxygenation. Interestingly, in the range of in vivo $\mathrm{pH}$ values, this 
$\mathrm{pH}$ independent venous reserve may be higher in Octopus dofleini (40\%) than in squid ( $<10 \%$ in Illex) suggesting that the more sluggish octopods may not rely on $\mathrm{pH}$ dependent deoxygenation to the same extent as their more active relatives (cf. Pörtner, 1990 b for a graphical presentation).

When $\mathrm{pH}$ fluctuations in the blood and the respective influences on haemocyanin oxygen binding are discussed, those processes which influence both arterial and venous $\mathrm{pH}$ must be distinguished from those which will only change venous $\mathrm{pH}$. An alkalosis in both arterial and venous blood will be caused by the observed release of excess base from the tissues. As discussed above and illustrated in Figure 6A (cephalic circulation) an alkalosis, which is only venous, would be the consequence of proton binding during deoxygenation being in excess of respiratory acidification. Further venous alkalization with constant arterial $\mathrm{pH}$ would result when the animals deplete any venous reserve during an increase in oxygen consumption.

Blood gas measurements in unrestrained squid were performed in samples withdrawn from the vena cava cephalica (Pörtner et al., 1991). According to the view prevailing in the literature this blood represents mixed venous blood. However, based on a large difference between mantle tissue intracellular $\mathrm{PcO}_{2}$ and vena cava $\mathrm{PCO}_{2}$ both in magnitude and in the pattern of changes we concluded that the cephalic vena cava values may not represent characteristic (or "mixed") venous values. This conclusion is supported by the morphology of cephalopods, vena cava blood being the venous return from the head and not from the mantle. Thus, there may be a functional difference between the respective parts of the circulatory system in that (owing to different ratios of blood flow over total metabolic oxygen requirement) most haemocyanin bound oxygen is released in the mantle, whereas venous blood returning from the head retains a venous reserve. This may be seen to protect oxygen transport to the highly sensitive brain under all conditions (see below). Similar conclusions result from a comparison of arterial and venous parameters reported in the literature, depending on whether venous parameters have been analysed in vena cava (cephalic) blood or in afferent branchial blood (mixed venous blood from head and mantle). A slight alkalosis or a minor acidosis in vena cava vs. arterial blood was found in Sepia officinalis $\left(\Delta \log \mathrm{P}_{50} / \Delta \mathrm{pH}=-1.6\right.$, Johansen et al., 1982) and in Octopus dofleini $\left(\Delta \log \mathrm{P}_{50} / \Delta \mathrm{pH}=-1.7\right.$, Johansen and Lenfant, 1966, Miller, 1985). In mixed venous (afferent branchial) vs. arterial blood the acidosis is greater as demonstrated in Octopus vulgaris $\left(\Delta \log \mathrm{P}_{50} / \Delta \mathrm{pH}=-1.1\right.$ to -1.7 ; Houlihan et al., 1982 , 1986; Brix et al., 1989) and in (restrained) Loligo pealei $\left(\Delta \log \mathrm{P}_{50} / \Delta \mathrm{pH}=-1.21\right.$; Redfield and Goodkind, 1929, cf. Pörtner, 1990 b) as well as in Illex illecebrosus (unpublished observations, samples taken from anaesthetized animals).

For the analysis of haemocyanin function in mantle tissue it is important that intracellular $\mathrm{PCO}_{2}$ is already high under control conditions (as found in lllex and Loligo) and increases even further during exercise (in Illex, Pörtner et al., 1991). Figures $6 \mathrm{~A}-\mathrm{D}$ illustrate the extent to which the respiratory situation would be different between cephalic blood collected from the vena cava and the blood returning from the mantle in squid. Gas exchange can be assumed to maintain more or less constant arterial gas tensions, based on the respective analyses and conclusions by Redfield and Goodkind (1929), Johansen and Lenfant (1966), Houlihan et al. (1986), and Wells (1990) arterial $\mathrm{PCO}_{2}$ is assumed to stay constant at two thirds of the vena cava control level. Therefore, model calculations (Pörtner, 1987 b) reveal the pattern of arterial and venous values under control conditions and their changes during fatiguing exercise and recovery. Tissue $\mathrm{PcO}_{2}$ can be assumed to come close to the 


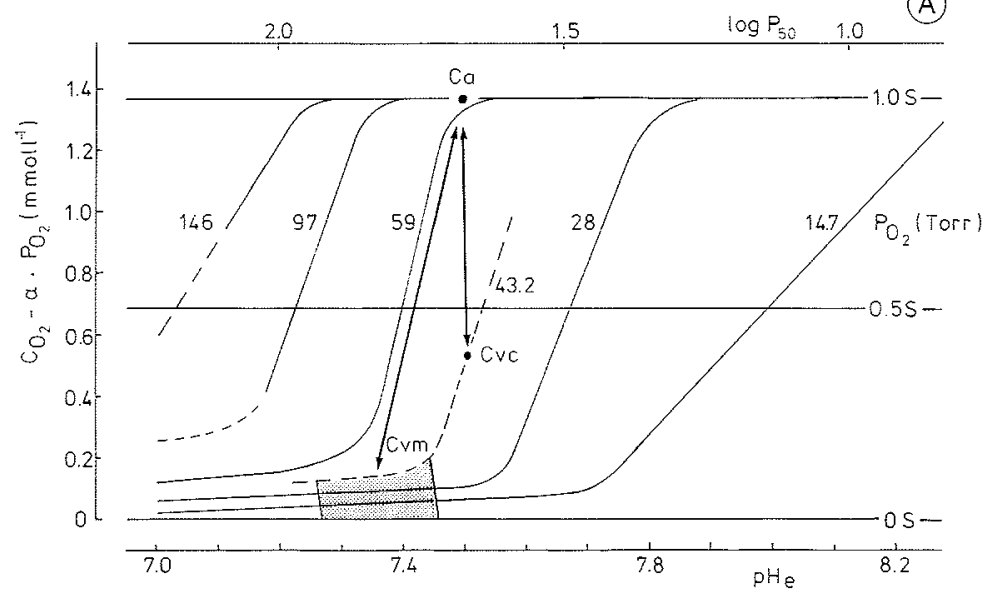

Figure 6A Control conditions. Oxygenation values in arterial and venous blood in the cephalic and the mantle circulations of Illex illecebrosus in $\mathrm{pH} /$ saturation diagrams $\left(\mathrm{T}=15^{\circ} \mathrm{C}\right)$. The oxygen isobars show the change in haemocyanin bound oxygen levels $\left(\mathrm{CO}_{2}-\alpha . \mathrm{Po}_{2}=\right.$ total oxygen content-physically dissolved oxygen $)$ with extracellular $\mathrm{pH}\left(\mathrm{pH}_{\mathrm{e}}\right)$ at constant $\mathrm{PO}_{2}$ (values in Torr). Horizontal lines intersect these isobars at fractional values of saturation (S) of $0,0.5$ (half saturation) and 1 (full saturation); the upper line depicts oxygen affinity (as $\log \mathrm{P}_{50}$ ) valid for the respective $\mathrm{pH}_{\mathrm{c}}$ at half saturation $(0.5 \mathrm{~S})$ and thus, the Bohr effect. Arterial and venous values are shown as measured in vena cava (i.e. venous cephalic) blood $(\mathrm{vc})$ in vivo and estimated from a quantitative treatment of the acid-base status for arterial (a) and venous mantle (vm) blood under control (C) conditions (Figure 6A), after exercise (E, Figure $6 B$ ), extreme performance (E', Figure $6 C$ ) and 10 min of recovery $(R$, Figure $6 D$ ). The shaded areas indicate the range of venous values of haemocyanin oxygenation in the mantle assuming a potential $\mathrm{PcO}_{2}$ gradient between muscle cells and blood from 0 to 3 Torr (dashed line $=\mathrm{PO}_{2}$ as measured in vena cava blood, numbers given in Torr, based on data by Pörtner et al., 1991). For further explanations and a discussion of the pattern of pH changes between arterial and venous blood see text.

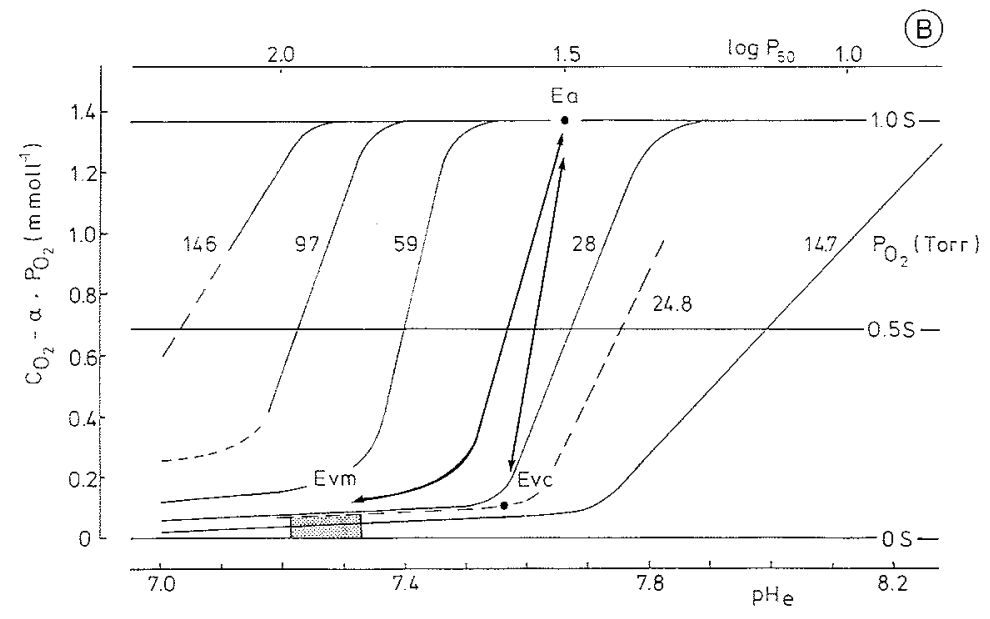

Figure 6B After exercise. 


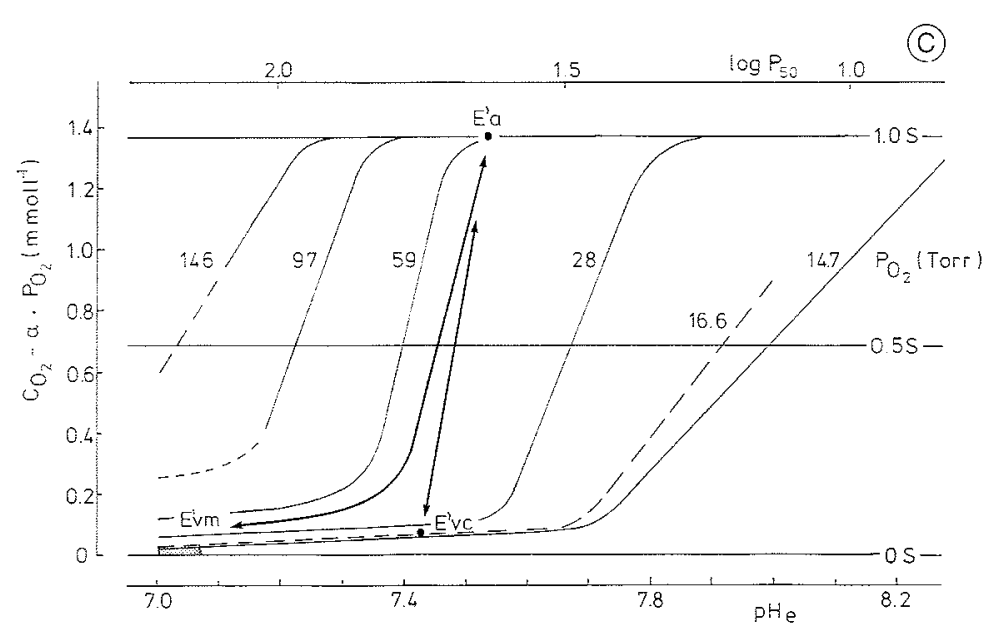

Figure 6C After extreme performance

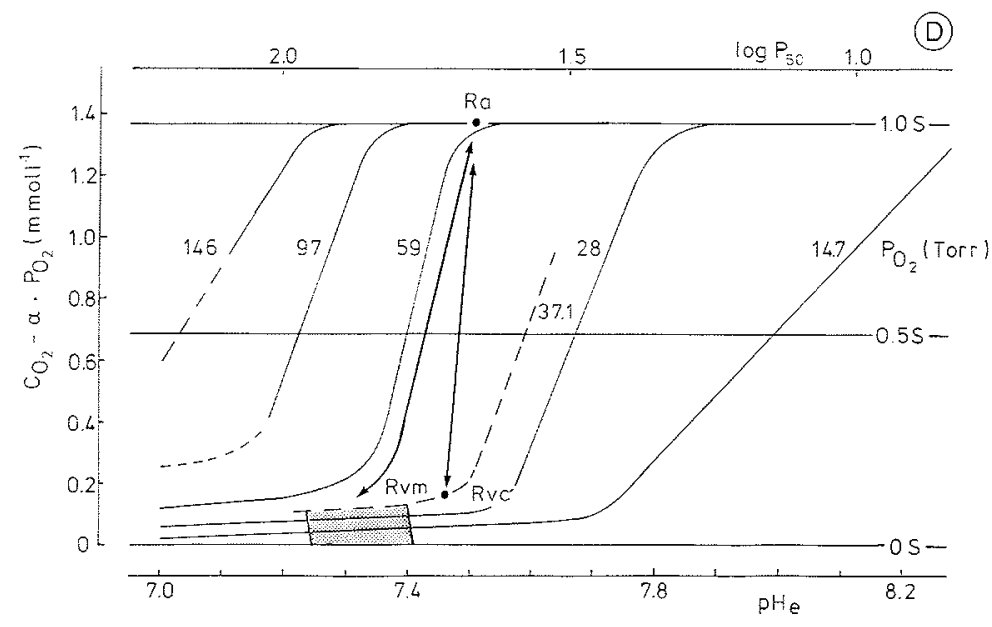

Figure 6D During recovery.

$\mathrm{PCO}_{2}$ of venous blood (ranges given in Figures $6 \mathrm{~A}-\mathrm{D}$ consider a maximum gradient of about 3 Torr between the intracellular and extracellular space, based on Pörtner et al., 1990 and Pörtner, unpublished). The depiction of the resulting $\mathrm{pH}$ changes in the $\mathrm{pH} /$ saturation diagrams (Figures $6 \mathrm{~A}-\mathrm{D}$ ) reveals the function of the Bohr effect and illustrates the $\mathrm{PO}_{2}$-buffer function of the pigment:

Rather than a ventilatory alkalosis during hypoxia (e.g. in Octopus or Sepia, Houlihan et al., 1982, Johansen et al., 1982), the release of base in squid uses the Bohr effect to enhance and protect arterial oxygen binding during exercise (see above). Otherwise, uncompensated metabolic or respiratory acidification during exercise could cause arterial $\mathrm{pH}$ to drop. Since arterial $\mathrm{Po}_{2}$ is unlikely to exceed 100 
Torr (cf. Redfield and Goodkind, 1929) this would soon (with a left-shift in the diagram by $0.1 \mathrm{pH}$ units below the $\mathrm{pH}$ under control conditions in Illex, Figure 6A) endanger arterial saturation. Therefore, the accumulation of base is a safeguard against a fatal arterial acidosis. As described above the beneficial effect of the base release on arterial oxygenation is maintained even during maximum metabolic acidification of the fatiguing mantle tissue (Figure 3 ).

These considerations indicate how the squid would respond to changes in environmental oxygen and carbon dioxide levels in their pelagic environment (cf. Redfield and Goodkind, 1929). Figures 4 to 6 reveal the respective thresholds. Under control condition $\mathrm{pH}$ values, Illex illecebrosus (at $15^{\circ} \mathrm{C}$ ) relies on minimum ambient $\mathrm{PO}_{2}$ values of 110 Torr (at constantly low $\mathrm{PcO}_{2}$ ) or a maximum ambient $\mathrm{PCO}_{2}$ value of 2.4 Torr (at normoxic $\mathrm{Po}_{2}$ values) to maintain oxygen transport. These values may change to lower oxygen or higher $\mathrm{CO}_{2}$ levels if the animals are able to shift arterial $\mathrm{pH}$ to higher values, as seen during exercise.

In the head, the slight alkalosis (in vena cava versus arterial blood) found in controls (Figure 6A) appears to increase during activity (Figures 6B,C) when the venous reserve is depleted. However, the quantity of base released during exercise shifts arterial pH in the alkaline direction, too, establishing an acidotic $\mathrm{pH}$ shift between arterial and cephalic venous blood. The venous reserve in vena cava blood is depleted under these conditions, with proton uptake being compensated for by respiratory acidification.

Under all conditions, respiratory acidification occurs in excess of the non-respiratory alkalization in venous mantle blood, supporting deoxygenation in accordance with the classical function of Bohr and Haldane effects and, thus, a $\mathrm{PO}_{2}$-buffer function of the haemocyanin. Owing to the high $\mathrm{PCO}_{2}$ gradient, blood $\mathrm{pH}$ in the mantle is up to 0.2 to $0.3 \mathrm{pH}$ units below arterial $\mathrm{pH}$ under control conditions (Figure 6A). Respiratory acidification during exercise causes venous pH to fall even further (Figures 6B,C). Under all conditions there is full utilization of the haemocyanin bound oxygen; virtually no venous reserve is present. Short term recovery (Figure 6D) leads to the rapid restoration of control values but a cycle of full oxygenation and deoxygenation of the haemocyanin is maintained in both the head and the mantle. The base release seen during exercise is reversed. Overall, this analysis confirms the early measurements of Redfield and Goodkind (1929), which indicated mixed venous $\mathrm{pH}$ in (stressed) squid to be significantly (by 0.12 units) below arterial $\mathrm{pH}$. Actually, the present study suggests that the use of stressed animals did not cause severe artefacts in Redfield and Goodkind's experiments.

The beneficial effect of base accumulation on arterial $\mathrm{O}_{2}$ binding may be balanced by the associated "disadvantage" that $\mathrm{PO}_{2}$ is buffered at lower values as the haemocyanin passes from the gills to venous sites, although such a shift to lower tissue $\mathrm{PO}_{2}$ values would support an increase in $\mathrm{O}_{2}$ uptake via the skin (cf. Figure 7, Table 1). The postulated position of the lines of $\mathrm{pH}$ and oxygenation changes between arterial and venous blood reffect the effect of the alkalization by a shift to the right (illustrated by the change between Figures $6 \mathrm{~A}$ and $\mathrm{B}$ ). This trend would be emphasized if the proton binding during deoxygenation occurs early and in a non-linear fashion as described by Connelly et al. (1989) for Octopus dofleini haemocyanin. However, a preliminary analysis (Pörtner, unpublished) suggests that this is not the case in Illex illecebrosus haemocyanin.

The actual pattern of $\mathrm{pH}$ changes between complete arterial oxygenation and more or less complete venous deoxygenation is difficult to predict. The patterns in the Figures $(6 \mathrm{~B}, \mathrm{C})$ assume that the $\mathrm{pH}$ change follows the respective (venous) oxygen 
isobar and is largely determined by the $\mathrm{PCO}_{2}$ increase with elevated buffer values during deoxygenation. In a low range of oxygenation, the buffer value would decrease and $\mathrm{pH}$ (and $\mathrm{PO}_{2}$ ) would drop to the measured values (cf. Figure 4). However, oxygen uptake via the skin may elevate $\mathrm{PCO}_{2}$ values in the tissues and cause an early acidification of the blood as it passes through. A left-shift of the in vivo curves would result, increasing the buffered $\mathrm{PO}_{2}$ values before deoxygenation sets in. These considerations demonstrate that the quantitative relationships between the oxygen binding characteristics of cephalopod haemocyanins and their function in vivo are still incompletely understood. They also demonstrate the usefulness of the $\mathrm{pH} / \mathrm{saturation}$ analysis as a framework for future quantitative studies of haemocyanin function.

\section{Skin oxygen uptake and carbon dioxide release}

The question arises where the $\mathrm{PcO}_{2}$ required for respiratory acidificiation originates, when Bohr and Haldane coefficients below -1 suggest an alkalosis in venous vs. arterial blood due to extensive proton binding during deoxygenation. With a respiratory quotient below 1 , a metabolic rate, which only consumes the oxygen carried in the blood, would provide steady state tissue $\mathrm{PCO}_{2}$ values which are too low to acidify venous blood and cannot compensate for the proton binding during deoxygenation. However, since haemocyanin function in cephalopods has always been analogized to haemoglobin function in vertebrates, the possibility that oxygen uptake via the skin may influence this picture has been overlooked (Pörtner, 1990 b). The thin skin of cephalopods, especially squid, may actually turn out to be an important accessory organ for oxygen uptake (and $\mathrm{CO}_{2}$ release). This is also suggested by the sandwich structure of the mantle tissue with aerobic fibres at the periphery and mitochondria-poor fibres in the core. In $500 \mathrm{~g}$ Illex approximately $6 \mathrm{~mm}$ mantle diameter would include aerobic layers ( $47 \%$ mitochondria) $0.8 \mathrm{~mm}$ on the outside and $0.3 \mathrm{~mm}$ on the inside (7\% mitochondria in the central, more anaerobic muscle cells; Bone et al., 1981, Mommsen et al., 1981). Capillarisation of the aerobic layers is much less (at least 5 to 8 times) than in aerobic muscle of fish (Bone et al., 1981) although the maximum rate of oxygen consumption is more than 2 times higher in squid (O'Dor and Webber, 1986). These observations would also support the conclusion that much of the oxygen consumed by the aerobic cells originates from the ambient water. Oxygen tensions at both the inner and outer mantle surface are high, especially in jetting squid where oxygen extraction from the water entering the mantle cavity remains far below 20\% (see Wells, 1990 and this volume). Additional oxygen consumption by peripheral mitochondria would be linked to increased $\mathrm{CO}_{2}$ generation and could, thus, cause $\mathrm{PcO}_{2}$ values in the tissue to rise up to those determined by Pörtner et al. (1991). Although diffusion gradients would cause part of this $\mathrm{CO}_{2}$ to leave the animal via the skin, simple partitioning should leave a large fraction to be trapped in the blood (supported by facilitated diffusion mechanisms for $\mathrm{CO}_{2}$ in tissue and blood, i.e. by the Haldane effect and, very likely, carbonic anhydrase reaction), thus causing respiratory acidification in accordance with elevated tissue $\mathrm{PCO}_{2}$ values.

The only experimental estimate of oxygen uptake via the skin is below $13 \%$ for Octopus vulgaris, but this estimate refers exclusively to the cutaneous respiration of web, arms and suckers (Wells and Wells, 1983). It remains to be established to what extent the thin fins of squid and sepia may cover their oxygen needs via skin oxygen uptake. Based on available data, Figure 7 and Table 1 provide an estimate of the 
percentage of $\mathrm{O}_{2}$-uptake via the skin for whole animals or for the mantle or head for those species proven not to rely on oxygen-linked $\mathrm{CO}_{2}$ binding (See above: as seen in Octopus vulgaris by Houlihan et al., 1982, the binding of carbon dioxide in arterial blood would cause an apparent discrepancy between blood-based RQ values, 0.7 , a low Bohr coefficient, -1.7 , and the actual finding of a venous acidosis). The table demonstrates that the calculation depends upon the accuracy of the RQ value and the quantification of $\mathrm{CO}$, transport in the blood. Table 1 considers a common RQ of 0.85 for protein catabolism, an RQ of 0.92 for proline metabolism and an $\mathrm{RQ}$ of 1 for carbohydrate oxidation. In Loligo pealei and Octopus dofleini the resulting fractions of skin oxygen uptake for whole animals are close to or higher than the estimate given above for the cephalic region of Octopus vulgaris. The estimate of mantle skin respiration, especially in active cruising squid, is rather insensitive to which of the three RQ values is used in the calculation and yields values higher than $50 \%$. Since the data in Figure 7 and Table 1 were calculated from a comparison of $\mathrm{O}_{2}$ and $\mathrm{CO}_{2}$ quantities in the blood, the actual values could be even higher depending on the $\mathrm{CO}_{2}$ fraction which leaves the tissue via the skin. If $\mathrm{CO}_{2}$ diffusion is over equal areas (outside vs. inside) and half is removed via the blood and gills, even higher fractions of the oxygen consumed by the mantle would be supplied via the skin (during exercise in Illex). Certainly, these values are preliminary results of model

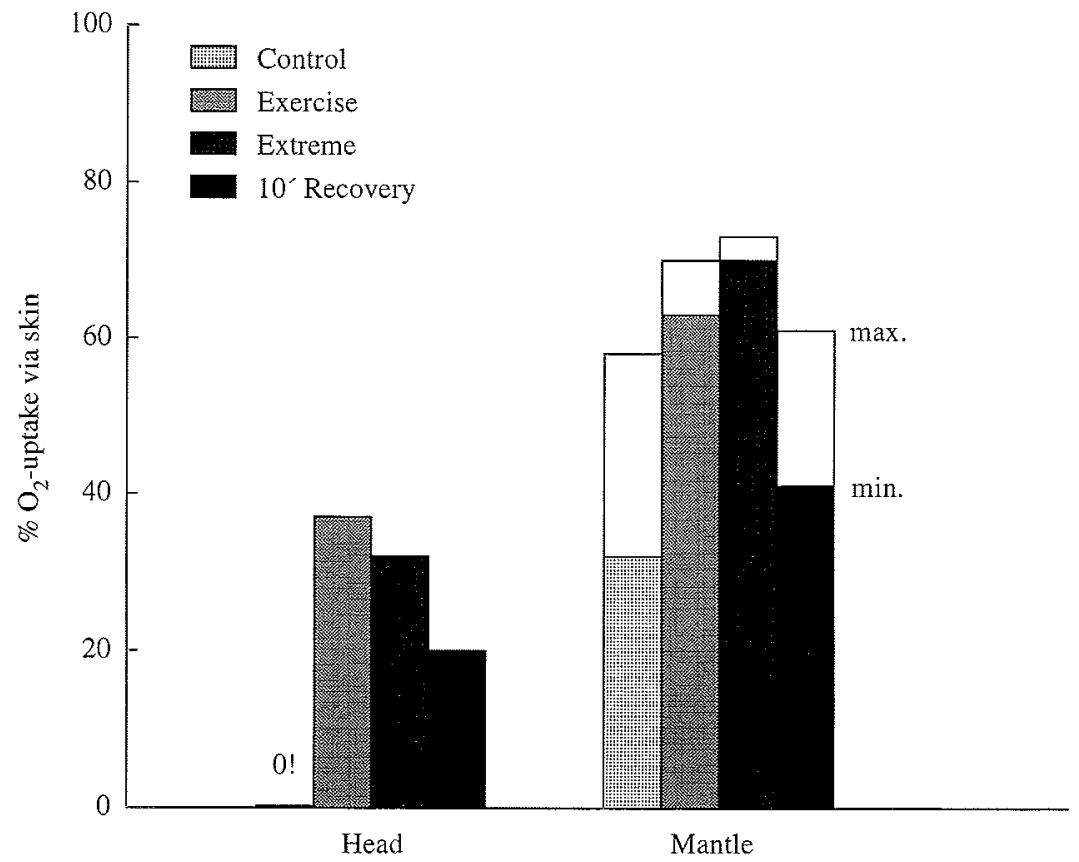

Figure 7 Estimates of the percent fractions of the oxygen consumed by the head or mantle of squid (Illex illecebrosus) which are taken up via the skin of the respective part of the body. The calculation is based on venous return from the respective organ and uses an RQ of 0.85 and the respective difference in the contents of $\mathrm{CO}$, and $\mathrm{O}$, between arterial and venous blood. It shows an increase of oxygen uptake via the skin during swimming activity. For details of the calculation and further explanations see Table 1 and text 
Table 1 Estimates of the percentages of oxygen uptake via the skin of squid or octopus (whole animal or head or mantle, based on mixed venous, afferent branchial blood or on venous return from the mantle or head). The calculation $\left(\left[\Delta \mathrm{Cco}_{2}-\mathrm{RQ} \cdot \mid \Delta \mathrm{Co}_{1}\right]\right] / \Delta \mathrm{CCO}_{2} \cdot 100=\% \mathrm{Mo}$, via the skin) uses different $\mathrm{RQ}$ values from protein $(0.85)$, proline $(0.92)$ and carbohydrate catabolism $(1.0)$ and the respective difference in the contents $\left(\mathrm{mmol} 1^{-1}\right)$ of $\mathrm{CO}_{2}\left(\Delta \mathrm{CcO}_{2}\right)$ and $\mathrm{O}_{2}\left(\Delta \mathrm{CO}_{2}\right)$ between arterial and venous blood of animals shown not to rely on oxygen-linked $\mathrm{CO}_{2}$ binding (see text, based on literature data for Octopus dofleini by Johansen and Lenfant, 1966, and for Illex illecebrosus by Pörtner et al., 1991. The respective data for Illex illecebrosus are depicted in Figure 7 . The analysis for head and mantle in Loligo pealei is supported by whole animal data recalculated from Redfield and Goodkind's study, see Pörtner, 1990 b). Note that these estimates are low estimates if, in addition, large quantities of $\mathrm{CO}_{2}$ leave the animal via the skin (see text). Negative estimates for skin oxygen uptake in the head of squid under control conditions are conceivable only if $\mathrm{CO}_{2}$ leaves the venous blood via the wall of the vena cava cephalica which runs along the ventral body surface inside the mantle cavity.

\begin{tabular}{|c|c|c|c|c|c|c|c|}
\hline species & condition & body region & $\Delta \mathrm{CcO}_{2}$ & $\Delta \mathrm{Co}_{2}$ & $\begin{array}{c}\% \mathrm{Mo}_{2} \\
\mathrm{RQ}=0.85\end{array}$ & $\begin{array}{r}\text { via } \\
0.92\end{array}$ & $\begin{array}{c}\text { skin } \\
1.0\end{array}$ \\
\hline \multirow{8}{*}{$\begin{array}{l}\text { 1. illece- } \\
\text { brosus }\end{array}$} & resting & head & +0.7 & -0.9 & $\approx 0$ & -18 & -29 \\
\hline & $\left(15^{\circ} \mathrm{C}\right)$ & mantle & $\begin{array}{l}+1.7 \\
\text { to } 2.8\end{array}$ & -1.4 & 32 to 58 & 25 to 54 & 18 to 50 \\
\hline & \multirow[t]{2}{*}{ exercise } & head & +1.9 & -1.4 & 37 & 33 & 26 \\
\hline & & mantle & $\begin{array}{l}+3.4 \\
\text { to } 4.1\end{array}$ & -1.5 & 63 to 70 & 59 to 66 & 56 to 63 \\
\hline & \multirow[t]{2}{*}{ extreme } & head & +1.8 & -1.5 & 32 & 24 & 17 \\
\hline & & mantle & $\begin{array}{l}+4.2 \\
\text { to } 4.7\end{array}$ & -1.5 & 70 to 73 & 67 to 70 & 64 to 68 \\
\hline & \multirow[t]{2}{*}{ recovery } & head & +1.4 & -1.3 & 20 & 15 & 7 \\
\hline & & mantle & $\begin{array}{l}+2.0 \\
\text { to } 3.1\end{array}$ & -1.4 & 41 to 61 & 36 to 57 & 30 to 55 \\
\hline \multirow[t]{3}{*}{ L. pealei } & \multirow{2}{*}{$\begin{array}{l}\text { resting } \\
\left(15^{\circ} \mathrm{C}\right)\end{array}$} & head & +0.8 & -1.0 & $\approx 0$ & -14 & -25 \\
\hline & & mantle & $\begin{array}{l}+2.9 \\
\text { to } 3.6\end{array}$ & -1.4 & 48 to 67 & 56 to 64 & 52 to 61 \\
\hline & $\begin{array}{l}\text { stressed } \\
\left(23^{\circ} \mathrm{C}\right)\end{array}$ & $\begin{array}{l}\text { whole } \\
\text { animal }\end{array}$ & +1.9 & -1.7 & 27 & 18 & 11 \\
\hline O. dofleini & $\begin{array}{l}\text { control } \\
\left(11^{\circ} \mathrm{C}\right)\end{array}$ & head & +1.5 & -1.3 & 28 & 21 & 13 \\
\hline
\end{tabular}

calculations which call for experimental verification. Such high oxygen uptakes via the skin cannot be explained by diffusion alone and may require enhanced microconvection and mixture of cell and tissue fluids during the contraction relaxation cycle (as indicated by the up to $100 \%$ change in mantle wall diameter during contraction), low blood and tissue $\mathrm{Po}_{2}$ values during exercise (see above), and high water currents to minimize boundary layers during swimming. The latter effect may explain why skin oxygen uptake in the head region is minimal at rest but rises during swimming. That skin oxygen uptake occurs predominantly via the mantle surface (and fins) rather than via the skin of the rest of the body explains the differences between vena cava, afferent branchial and venous mantle blood gas parameters derived from various studies (see above). The return of these modern cephalopods to the ancient mode of cutaneous gas exchange may enable them to achieve metabolic rates far exceeding the maximum rate of oxygen provision possible via the blood. The low blood oxygen carrying capacity would otherwise call for a circulatory system in squid with performance characteristics exceeding those of the mammalian 
circulation (see Shadwick et al., 1990; Shadwick, this volume). The price for such a costly life style would, however, be a limited maximum body size of those muscular forms which rely on skin oxygen uptake to the extent calculated for Illex illecebrosus. A Bohr factor of -0.8 as found in Architeuthis monachus (Brix et al., 1989), suggests that gas exchange via the skin may not be important in the large ammoniacal squids.

\section{SUMMARY AND CONCLUSIONS}

The picture gained from exercising squid could provide a general hypothesis for the coordination of metabolism, acid-base regulation and blood pigment function in cephalopods. They maintain acid-base parameters in the blood regardless of metabolic acidification in the tissues. When environmental parameters remain more or less constant, emphasis is on respiratory changes in the acid-base status to cause venous acidification and to modulate haemocyanin oxygen transport to tissues. Large Bohr and Haldane effects are found in many cephalopods as well as large $\mathrm{pH}$ dependent cooperativities (Pörtner, 1990 b). The high sensitivity to pH can support a steady distribution of oxygen within the tissue via the blood. This steadiness of distribution is indicated by the linear slope of the oxygen isobars in the $\mathrm{pH} / \mathrm{saturation}$ diagram and is linked to well buffered $\mathrm{PO}_{2}$ values until the bound oxygen is depleted. $\mathrm{pH}$ and, thus, oxygen binding in arterial blood are highly protected as indicated by a base loss from the tissues during exercise, suitable to balance the threat of excess respiratory acidification. Owing to the large $\mathrm{pH}$ dependence of oxygen binding, especially in squid, there is only a minor venous reserve accessible by additional acidification and/or a decrease in venous $\mathrm{PO}_{2}$. Maximum slopes of the oxygen isobars in the range of in vivo $\mathrm{pH}$ and $\mathrm{Po}_{2}$ suggest that the oxygen transport system is designed to respond to even the smallest changes in the extracellular acid-base status. As a corollary, non-respiratory and respiratory mechanisms of acid-base regulation are finely controlled to support and optimize haemocyanin function in these animals.

Oxygen uptake via the skin actually allows an explanation for the large Bohr and Haldane effects observed in many cephalopods. Large Bohr and Haldane effects may be an adaptive response to the increase in body surface as modern cephalopods lost their shells. This may be linked to increased performance, increased oxygen uptake via the skin and, thus, respiratory acidification of tissues and blood. The development of a thin, delicate skin, permeable to $\mathrm{O}_{2}$ (and $\mathrm{CO}_{2}$ ) especially in highly tuned muscular squid, would support this explanation. It is also supported by the observation that Nautilus pompilius as a living representative of ancient forms does not possess a Bohr effect as large as that found in the modern cephalopods $\left(\Delta \log \mathrm{P}_{50} / \Delta \mathrm{pH}=-0.2 ;\right.$ Johansen et al., 1978). Future experiments must show whether oxygen-linked $\mathrm{CO}_{2}$ binding may, additionally, have evolved to maximize the $\mathrm{PO}_{2}$ buffer function of the haemocyanin even further in those forms where oxygen uptake via the skin remained or became less important (like "burrowing" Sepia or benthic Octopus vulgaris or larger squid, especially the giant squid, Architeuthis).

\section{Acknowledgements}

Supported by grants of the Deutsche Forschungsgemeinschaft. The author wishes to thank Martin Wells and Ron O'Dor for stimulating discussions. Alfred-WegenerInstitute Publication No. 772. 


\section{References}

Agnisola, C., Driedzic, W. R., Foster, A. R., Houlihan, D. F., and Stewart, J. M. (1991) Oxygen consumption, carbon dioxide production and enzyme activities of isolated working Octopus heart. J. exp. Biol., 157, 543-549.

Bone, Q., Pulsford, A. and Chubb, A. D. (1981) Squid mantle muscle. J. mar. biol. Ass. U.K., 61, $327-342$.

Bridges, C. R.(1994) Bohr and Root effects in cephalopod haemocyanins - paradox or pressure in Sepia officinalis. Mar. Behav. Physiol. (this volume)

Brix, O., Lykkeboe, G. and Johansen, K. (1981) The significance of the linkage between the Bohr and Haldane effects in cephalopod bloods. Respir. Physiol., 44, 177-186.

Brix, O., Bardgard, A., Cau, A., Colosimo, A., Condo, S. G. and Giardina, B. (1989) Oxygen-binding properties of cephalopod blood with special reference to environmental temperatures and ecological distribution. J. exp. Zool., 252, $34-42$.

Brix, O., Colosimo, A. and Giardina, B. (1994) Temperature dependence of oxygen binding to cephalopod hacmocyanins: ecological implications. Mar. Behav. Physiol. (this volume)

Connelly, P. R., Gill, S. J., Miller, K. I., Zhou, G. and van Holde, K. E. (1989) Identical linkage and cooperativity of oxygen and carbon monoxide binding to Octopus dofleini hemocyanin. Biochem., $24,4582-4586$.

Gäde, G. (1980) Biological role of octopine formation in marine molluscs. Mar. Biol. Lett., 1, $121-135$.

Grieshaber, M. and Gäde, G. (1976) The biological role of octopine in the squid, Loligo vulgaris (Lamarck). J. Comp. Physiol., 108, 225 -232.

Heisler, N. (1986) Buffering and transmembrane ion transfer processes. In Acid-base Regulation in Animals, N. Heisler (ed.), pp. 3-47. Elsevier Biomedical Press, Amsterdam.

Houlihan, D. F., Innes, A. J., Wells, M. J. and Wells, J. (1982) Oxygen consumption and blood gases of Octopus migaris in hypoxic conditions. J. comp. Physiol., 148 B, 35-40.

Houlihan, D. F., Duthie, G., Smith P. J., Wells, M. J. and Wells, J. (1986) Ventilation and circulation during exercise in Octopus vulgaris. J. comp. Physiol. 156 B, 683-689.

Johansen, K. and Lenfant, C. (1966) Gas exchange in the cephalopod, Octopus dofteini. Am. J. Physiol., 210, $910-918$

Johansen, K., Redmond, J. R., Bourne, G. B. (1978) Respiratory exchange and transport of oxygen in Nautilus pompilius. J. exp. Zool, 205, 27-36.

Johansen, K., Brix, O. and Lykkeboe, G. (1982). Blood gas transport in the cephalopod, Sepia officinalis. J. exp. Biol., 99, 331-338.

Lee, P. G. (1994) Nutrition of cephalopods: fueling the system. Mar. Behas. Physiol. (this volume).

Lykkeboe, G., Brix, O and Johansen, K. (1980) Oxygen-linked $\mathrm{CO}_{2}$ binding independent of pH in cephalopod blood. Nature, Lond., 287, 330-331.

Lykkeboe, G. and Johansen, K. (1982) A cephalopod approach to rethinking about the importance of the Bohr and Haldane effects. Pac. Sci., 36, 305-313.

Mangum, C. P. (1990) Gas transport in the blood. In Squid as experimental animals, D. L. Gilbert, W. J. Adelman and J. M. Amold (eds), pp. 443-468. Plenum Press, New York.

Miller, K. I. (1985) Oxygen equilibria of Octopus dofleini haemocyanin. Biochem., 24, 4582-4586.

Miller, K. I. and Mangum, C. P. (1988) An investigation of the nature of Bohr, Root, and Haldane effects in Octopus dofleini hemocyanin. J. comp. Physiol., 158, 547-552.

Mommsen, T. P., Ballantyne, J., MacDonald, D., Gosline, J. and Hochachka, P. W. (198I) Analogues of red and white muscle in squid mantle. Proc. Natl. Acad. Sci. USA, 78, 3274-3278.

O'Dor, R. K. and Webber, D. M. (1986) The constraints on cephalopods: why squid aren't fish. Can. J. Zool., 64, 1591-1605.

O'Dor, R. K., Pörtner, H. O. and Shadwick, R. E. (1990) Squid as elite athletes: Locomotory, respiratory and circulatory integration. In Squid as Experimental Animals, D. L.Gilbert, W. J. Adelman and J. M. Arnold (eds), pp. 481-503. Plenum Press, New York.

Pörtner, H. O. (1987 a) Contributions of anaerobic metabolism to $\mathrm{pH}$ regulation in animal tissues: theory. J. exp. Biol., 131, 69-87.

Pörtner, H. O. (1987 b) Anaerobic metabolism and changes in acid-base status: Quantitative interrelationships and $\mathrm{pH}$ regulation in the marine worm Sipunculus nudus. J. exp. Biol., 131, 89-105.

Pörtner, H. O. (1990 a) Determination of intracellular buffer values after metabolic inhibition by fluoride and nitrilotriacetic acid. Respir. Physiol., 81, 275-288.

Pörtner, H. O. (1990 b) An analysis of the effects of $\mathrm{pH}$ on oxygen binding by squid (Illex illecebrosus, Loligo pealei) haemocyanin. J. exp. Biol., 150, 407-424.

Pörtner, H. O., Boutilier, R. G., Tang, Y. and Toews, D. P. (1990) Determination of intracellular pH and $\mathrm{PCO}_{2}$ after metabolic inhibition by fluoride and nitrilotriacetic acid. Respir. Physiol, 81, 255-274. 
Pörtner, H. O., Webber, D. M., Boutilier, R. G. and O’Dor, R. K. (1991) Acid-base regulation in exercising squid (Illex illecebrosus, Loligo pealei). Am. J. Physiol., 261, R239-R246.

Pörtner, H. O., Webber, D. M., O'Dor R. K. and Boutilier, R. G. (1993) Metabolism and energetics in squid (Illex illecebrosus, Loligo pealei) during muscular fatigue and recovery. Am. J. Physiol. 265, R157-R165.

Redfield, A. C. and Goodkind, R. (1929) The significance of the Bohr effect in the respiration and asphyxiation of the squid, Loligo pealei.J. exp. Biol., 6, 340-349.

Shadwick, R. E. (1994) Mechanical organization of the mantle and circulatory system of cephalopods. Mar. Behav. Physiol. (this volume).

Shadwick, R. E., O'Dor, R. K. and Gosline, J. M. (1990) Respiratory and cardiac function during exercise in squid. Can J. Zool., 68, 792-798.

Wells, M. J. (1990) Oxygen extraction and jet propulsion in cephalopods. Can. J. Zool., 68, 815-824.

Wells, M. J. (1994) The evolution of a racing snail. Mar. Behav. Physiol.(this volume)

Wells, M. J. and Wells, J. (1983) The circulatory response to acute hypoxia in Octopus. J. exp. Biol., $104,59-71$.

Wyman, J. (1964) Linked functions and reciprocal effects in hemoglobin: A second look. Adv. Protein Chem, 19, 223-286. 